\title{
Maternal-Fetal Circadian Communication During Pregnancy
}

\author{
Keenan Bates and Erik D. Herzog* \\ Department of Biology, Washington University, St. Louis, MO, United States
}

This article reviews evidence for maternal-fetal communication about the time of day. We explore the hypothesis that key maternal hormones synchronize daily rhythms in the fetus to regulate gestation duration. These findings may help to predict and prevent preterm birth.

Keywords: daily rhythm, parturition, melatonin, glucocorticoid, dopamine

\section{INTRODUCTION}

Circadian rhythms in gene expression and hormones are ubiquitous across species and across cell types $(1,2)$. Familiar examples include daily rhythms in sleep and wake, the nightly rise in melatonin secretion seen in most vertebrates, and the Nobel-prize winning discoveries in fruit flies showing how the Period gene negatively regulates its own transcription by repressing the transcription factors, CLOCK and BMAL1, on a daily basis $(3,4)$. To be useful, these daily rhythms in cells must be synchronized within the body and to the local light-dark cycle. This review focuses

OPEN ACCESS

Edited by:

Christian Benedict,

Uppsala University, Sweden

Reviewed by:

Henrik Oster

University of Lübeck, Germany Kathryn Reid,

Northwestern University, United States

${ }^{*}$ Correspondence:

Erik D. Herzog

herzog@wustl.edu

Specialty section:

This article was submitted to Translational Endocrinology,

a section of the journal

Frontiers in Endocrinology

Received: 11 December 2019

Accepted: 19 March 2020

Published: 15 April 2020

Citation:

Bates K and Herzog ED (2020)

Maternal-Fetal Circadian

Communication During Pregnancy.

Front. Endocrinol. 11:198.

doi: 10.3389/fendo.2020.00198 on how signals during pregnancy can synchronize daily rhythms between the mother and the fetus.

Daily rhythms depend on clock genes. A transcriptional-translational negative feedback loop generates the near-24 h cycles in most mammalian cell types. BMAL1 and CLOCK, two basic helix-loop-helix-PAS domain transcription factors, heterodimerize, and initiate the transcription of the Period (Per1, Per2, and Per3) and Cryptochrome (Cry1 and Cry2) genes (4). The PER and CRY proteins heterodimerize and translocate into the nucleus where they inhibit their own transcription by repressing the activity of BMAL1 and CLOCK (4). As transcript levels decline, the PER and CRY proteins degrade, so that BMAL1 and CLOCK can bind together to activate transcription again (4). Our understanding of the molecular mechanisms underlying circadian rhythms in processes including gene expression, hormone secretion, and their disruption in disease have been reviewed eloquently elsewhere (4-7).

Although circadian rhythms have been studied heavily in a wide variety of organisms, there has been substantial bias to examine chronobiology in males. For example, nearly all studies of the hypothalamic suprachiasmatic nucleus ( $\mathrm{SCN})$, a master circadian pacemaker in vertebrates, have been done in males despite early reports of its sexual dimorphism and its role in female endocrinology in humans and other mammals (8-13). Mammalian pregnancy presents a unique situation to study the importance of female circadian biology with daily rhythms in the mother and, later in the pregnancy, rhythms in the fetus which synchronize to each other and to local time (14-17).

\section{CRITERIA FOR CANDIDATE MATERNAL-FETAL CIRCADIAN COUPLING FACTORS}

Over the course of pregnancy, the hormonal profile changes to adapt to the needs of the developing fetus (see Table 1). Changes in some of these hormones (e.g., prolactin derived from the mother or lactogens from the fetal placenta) coincide with critical developmental events. Here, we 
TABLE 1 | Maternal hormone concentration and peak concentration time in each trimester and in non-pregnant women.

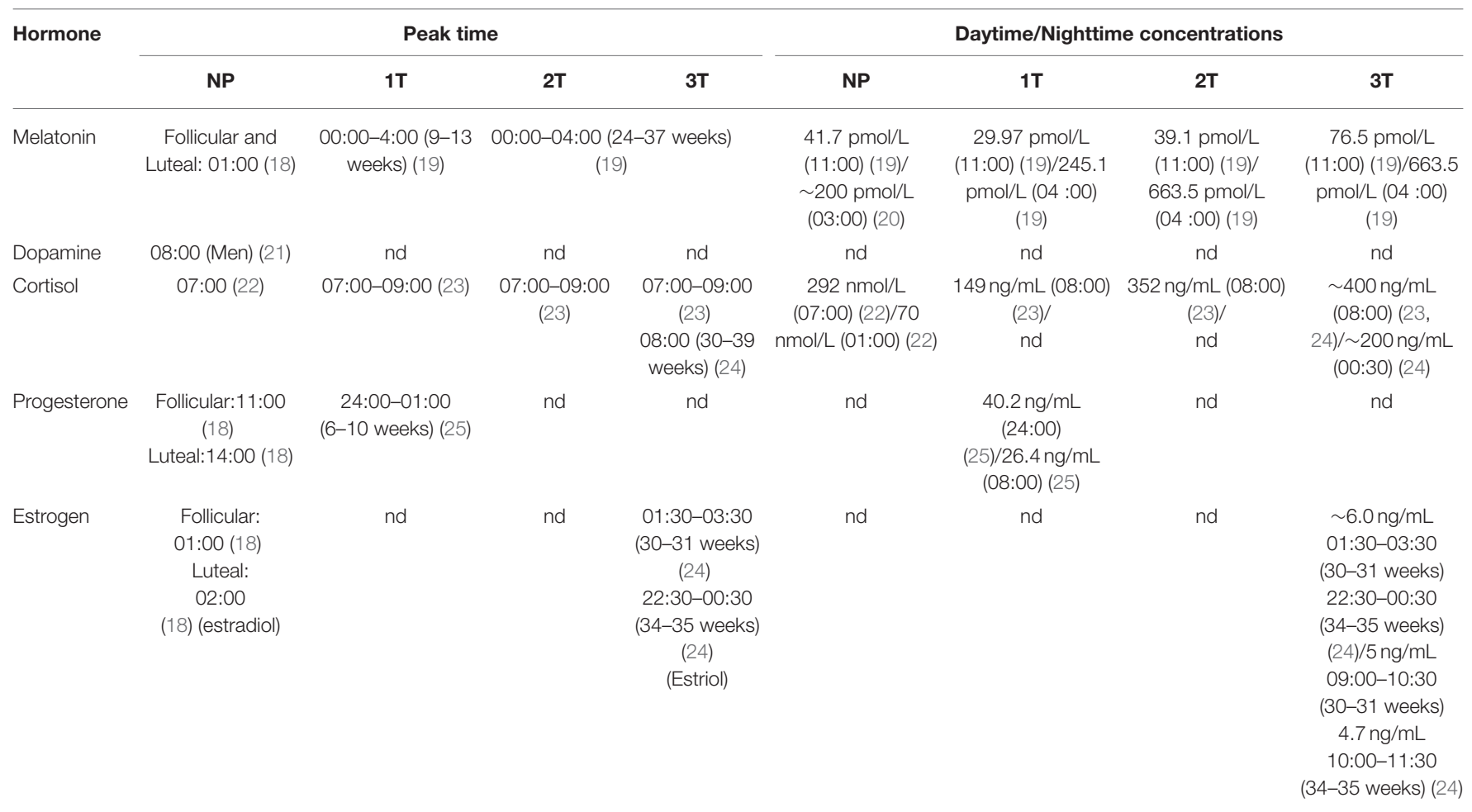

${ }^{\# \#}$ Relevant reference for peak time and concentration in parentheses.

NP, Non-pregnant; 1T, First Trimester; 2T, Second Trimester; 3T, Third Trimester.

Nd, No data.

Peak time: Time of day of sample collection and (gestational age of measurements).

Day/Night: concentrations and (time of day of sample collection).

seek to identify maternal signals that can synchronize fetal circadian rhythms and vice versa. We focus on hormonal signals which are strong candidates for communicating time of day information. We limit our discussion to factors that fulfill these five criteria:

1. Humoral factors,

2. derived either from the mother or the fetus,

3. produced in a circadian pattern during pregnancy,

4. with complimentary receptor distributions, and

5. capable of crossing the placental barrier.

\section{MATERNAL CIRCADIAN RHYTHMS ENTRAIN RHYTHMS IN THE FETUS}

The maternal SCN has an important role in providing circadian entraining signals to the fetus. Reppert and Schwartz (14) provided the first evidence for in utero daily rhythms when they showed that the fetal rat SCN had higher glucose utilization during the day than at night beginning on embryonic day 19 (E19), 3 days prior to birth $(14,26)$. When the dam underwent a 12-h shift in the light-dark schedule, the rhythm in glucose utilization in the fetal SCN exhibited a matching phase shift (14). Blinding the mother prior to altering the lighting schedule prevented a phase shift in the mother and the fetus (14). Additionally, lesioning the maternal SCN or knocking out the maternal core clock genes, Per1 and Per2, prevented entrainment of the fetal circadian system $(15,27)$. In vitro results demonstrated that fetal SCN can develop a rhythm (28-30). This leads to the hypothesis that input from the maternal circadian system entrains fetal daily rhythms. Candidate maternal signal(s) or signals responsible for fetal circadian entrainment include melatonin, glucocorticoids, and dopamine (31).

\section{MATERNAL TO FETAL COMMUNICATION}

Melatonin, dopamine, and corticosterone represent the three best-studied candidates for maternal-to-fetal communication of circadian rhythms. Each of these hormones has been tested for their capacity to synchronize fetal circadian rhythms in vivo or in vitro. None of these, however, are necessary for entrainment of the fetal circadian rhythm indicating there are parallel or compensatory pathways by which the mother can coordinate daily timing in her offspring.

\section{MELATONIN}

\section{Evidence for Rhythmic Expression in Humans and Rodents}

The pineal gland secretes melatonin at night under control of a multi-synaptic pathway from the retina, SCN, and spinal 


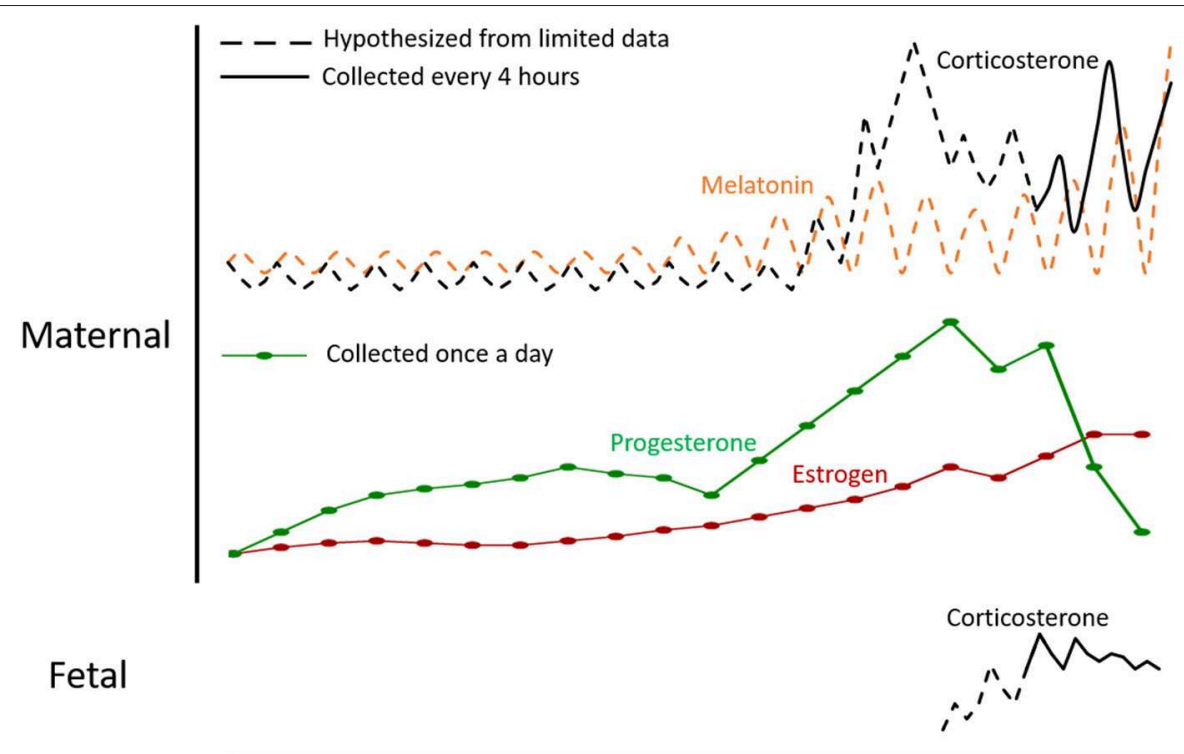

\begin{tabular}{l|l|l|l|l|l|l|l|l|l|} 
E2 & E4 & E6 & E8 & E10 & E12 & E14 & E16 & E18 & P0
\end{tabular}

FIGURE 1 | Schematic of hormone profiles over the course of the mouse pregnancy. Maternal hormones with a diurnal pattern are strong candidates for entraining fetal circadian rhythms and development. Hormone profiles throughout gestation have been measured (solid lines) or inferred (dashed lines) based on limited data (34-36). Melatonin and corticosterone are the major maternal hormones known to have circadian rhythms during pregnancy although other humoral signals like progesterone and estrogen could play a role. Fetal hormones such as corticosterone can also show circadian patterning and contribute to normal gestation.

cord $(3,32)$. Melatonin secretion depends on the environmental photoperiod, the length of time of light exposure (33). During the short days of winter, for example, more melatonin is secreted (33).

Detailed studies on the rhythmic secretion of melatonin during pregnancy are limited (Figure 1). However, they do suggest that nighttime melatonin levels change during pregnancy. In pregnant rats, daytime levels of melatonin measured $7 \mathrm{~h}$ after daily lights on (Zeitgeber time 7, ZT7) remained the same as in non-pregnant rats, but nighttime (ZT19) melatonin levels gradually increased after embryonic day 12 (E12) and peaked right before parturition (34). Melatonin returned to non-pregnant levels by postpartum day 2 (34). In humans, there was a similar pattern in secretion. In one study, daytime melatonin levels did not change over pregnancy while nighttime serum melatonin increased significantly at 32 weeks compared to 24 weeks of pregnancy and returned to non-pregnant levels on postpartum day 2 (37). However, this study was limited to two daily measurements (at 2:00 a.m. and 2:00 p.m.) during the second and third trimester. In a separate study, daytime and nighttime serum melatonin were significantly higher in the third trimester compared to the first and second (19). The peak time of melatonin secretion did not change between the early pregnancy (9-13 weeks) and late pregnancy (24-37 weeks). (19). In both groups of women, serum melatonin exhibited diurnal variation with a peak between midnight and 4:00a.m., consistent with the peak time found in non-pregnant women (19). This study did not follow the same women throughout their pregnancy; instead, they utilized samples from different women who were either in their first, second, or third trimester. Future work should track how daily profiles of melatonin change their level and timing in individual term and pre-term pregnancies.

\section{Evidence for Maternal-to-Fetal Transfer}

When melatonin is administered to rats and humans during pregnancy, it passes through the placenta into the fetal circulation unaltered $(38,39)$. In E21 pregnant rats, $\sim 75 \%$ of radioactive $\left[{ }^{125} \mathrm{I}\right]$ iodo-melatonin was found in fetal cardiac blood six minutes after tail vein injection (39). In humans, similar levels of serum melatonin occur in the maternal umbilical circulation (38). Administration of melatonin to term women led to a comparable increase in serum melatonin levels in the maternal and umbilical circulation (38). These results indicate that maternal melatonin can reach the fetus although when and how quickly remain unknown.

\section{Evidence for Fetal Expression of the Receptor(s)}

Melatonin receptors are widespread in fetal tissues and the placenta $(40,41)$. Melatonin begins binding to receptors in the fetal rat SCN on E18, 1 day after SCN neurogenesis (41). In humans, melatonin binding in the SCN occurs at 18-19 weeks of gestation (42). However, it has not been determined whether binding occurs prior to 18 weeks. 


\section{Evidence Hormone Is Necessary/Sufficient to Entrain Fetus}

Daily rhythms in maternal melatonin likely act as an indicator of the maternal circadian time and entrain the fetus to the environment (41). Exogenous administration of melatonin to SCN-lesioned pregnant hamsters caused their pups to have synchronized behavioral rhythms after birth depending on the time of day of the injections in utero (43). Maternal pinealectomy of rats early in gestation caused the neonatal pups to be less synchronized in their drinking activity compared to control mice (44). Injections of exogenous melatonin to pinealectomized rats late in gestation was sufficient to synchronize the drinking rhythms of the pups (44).

However, entrainment of the fetus to the maternal schedule does not require melatonin $(45,46)$. Mouse strains which lack melatonin production still show daily rhythms in physiology and behavior that appear synchronized among the offspring. Furthermore, pinealectomy of rat dams failed to prevent entrainment of fetuses to the maternal daily schedule (47).

In summary, daily melatonin levels increase in amplitude, but do not appear to change their phase, over the course of pregnancy. Melatonin readily crosses the placenta to enter the fetal circulation where melatonin receptors are found prior to birth. It suffices to entrain the fetus when administered exogenously at different times of day, but it is not necessary for entrainment, suggesting it acts as a redundant signal to entrain the fetus. Future work should help us to understand how rhythmic expression of melatonin may change and impact fetal daily rhythms over the course of a healthy pregnancy in women.

\section{DOPAMINE}

\section{Evidence for Rhythmic Expression in Humans and Rodents}

Early studies using in utero injections also implicated dopamine as maternal signal to time fetal circadian rhythms. Daily expression of dopamine during pregnancy has not been studied in either humans or rodents, but two studies in pregnant rhesus macaques provided some evidence for circadian regulation (48, 49). In one study, pregnant rhesus macaques had blood collected every three hours from 127 to 135 days of gestation (term $=$ 167 days) (48). Maternal plasma and amniotic fluid dopamine levels did not exhibit significant changes with time of day (48). In the second study which collected maternal plasma from 129 to 154 days of gestation, dopamine levels were higher during the morning $(0900$ and 1,200$)$ than at night $(2,400,0300$, and 0600) (49). In humans, there are no studies examining diurnal variation of plasma dopamine in women, but there has been one study on men. Plasma dopamine levels in men peaked around waking $(\sim 8: 00$ a.m.) and were at their nadir in the middle of sleep ( 3:00 a.m.) (21). Because prolactin, estrogen, and dopamine have an antagonistic relationship in the brain with dopamine levels rising when prolactin levels decrease and vice versa (50), it will be important to look for sex differences in daily dopamine profiles. Considering circulating levels of prolactin and estrogen change during menstruation and pregnancy (51), future work should also compare daily dopamine levels in non-pregnant and pregnant women.

\section{Evidence for Maternal-to-Fetal Transfer}

Dopamine may cross the placenta and enter the fetal circulatory system. Women showed an increase in dopamine concentration in the amniotic fluid between the second (15-20 weeks of gestation) and third trimester (36-41 weeks), but not in maternal or fetal plasma (52). The amniotic fluid concentration had a 15fold increase and was significantly higher than fetal and maternal plasma levels (52).

In pregnant rats, dopamine levels in fetal plasma decreased, in amniotic fluid increased while maternal plasma levels did not change from E18-E22 $(53,54)$. Some of the increase in dopamine levels in the amniotic fluid is likely from conversion of fetal Ldopa, but it is not understood what proportions of the amniotic fluid dopamine levels are contributed by the mother and fetus (55). In E19 pregnant rats injected with radioactive dopamine, the fetal plasma had half the concentration found in the maternal plasma $1 \mathrm{~h}$ after the injection (56).

\section{Evidence for Fetal Expression of the Receptor(s)}

$\mathrm{D}_{1}$ dopamine receptors are widely found in the fetal rat brain at E20 (57). At E18, $D_{1}$-dopamine receptors are found in the SCN (58). Injections on E19 with the $\mathrm{D}_{1}$ agonist SKF 38393 caused c-fos- induction in the fetal SCN. In humans, $\mathrm{D}_{1}$ receptors were found in the SCN at 22 weeks of gestation (59). However, it is unknown whether expression occurs prior to 22 weeks and how it may change at different stages of pregnancy.

\section{Evidence Hormone Is Necessary/Sufficient to Entrain Fetus}

Dopamine can affect fetal circadian timing. One injection given on E15 (birth occurs on E16) to SCN-lesioned hamsters produced pups with daily locomotor activity starting approximately 12$\mathrm{h}$ apart depending on whether the mother received melatonin or dopamine (60). Melatonin and dopamine are known to act antagonistically in the chick retina by modulating intracellular cAMP levels (61).

In summary, dopamine, like melatonin, could fulfill the criteria as circadian entraining signals. Dopamine levels vary with time of day during pregnancy in some studies, but we need better measurements in women. In rodents, dopamine crosses the placenta to enter the fetal circulation where $D_{1}$ receptors are found prior to birth and exogenous dopamine can shift fetal rhythms in anti-phase to melatonin, but there remains much we do not know about when and how endogenous dopamine may entrain the fetus.

\section{CORTICOSTERONE}

\section{Evidence for Rhythmic Expression in Humans and Rodents}

Glucocorticoids, such as corticosterone, are released in response to stress, but also exhibit a circadian rhythm in their release (62). Serum corticosterone peaks just prior to activity onset, 
driven by the SCN (62). SCN lesioning abolishes corticosterone rhythms (63).

There is limited data on the rhythmic expression of glucocorticoids over the course of pregnancy. In humans, serum cortisol peaked a few hours after waking throughout pregnancy with the morning peak progressively increasing between weeks 11 and 22 and then remaining high until initiation of labor (23). A second study found similar daily cortisol profiles from weeks 30-39 of pregnancy (24). Mice also showed an increase in the morning levels of maternal serum corticosterone starting around E11-E14, but with the peak occurring near the beginning of the night, their locomotor active phase (35).

\section{Evidence for Maternal-to-Fetal Transfer}

Corticosterone and other glucocorticoids are important to the maturation of several fetal organs $(64,65)$. In mice, fetal serum corticosterone levels are a product of maternal corticosterone that has crossed the placental barrier and corticosterone produced from the fetal adrenal cortex (66). Knocking out the corticotropin-releasing hormone $(\mathrm{CRH})$ gene $(\mathrm{Crh})$ in the dam and the fetuses, caused the fetuses to die following birth due to underdeveloped lungs (67). However, when the mother is heterozygous $\left(\mathrm{Crh}^{+/-}\right)$for the $\mathrm{Crh}$ gene while the fetuses are knockouts $\left(\mathrm{Crh}^{-1-}\right)$, the fetuses exhibited normal development of their lungs through placental transport of maternal corticosterone (67). $\mathrm{Crh}^{+/-}$dams with $\mathrm{Crh}^{-/-}$fetuses did exhibit day-night differences in fetal corticosterone at E16.5, suggesting that maternal-derived corticosterone crosses the placenta in a rhythmic manner (66). The placenta regulates glucocorticoid passage from the mother to the fetus through $11-\beta$

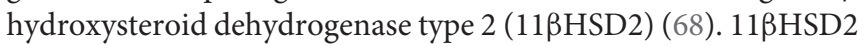
metabolizes most of the maternal glucocorticoids, preventing them from crossing the placenta and entering the fetal blood (68). Thus, the daily rhythm in maternal corticosterone release, placental transport, and metabolism by $11 \beta \mathrm{HSD} 2$ appears to produce peak fetal corticosterone levels at night (66). It will be intriguing to learn whether the presence of, or daily rhythm in, glucocorticoids is critical for fetal development.

\section{Evidence for Fetal Expression of the Receptor(s)}

Although there are no studies on the expression of glucocorticoid receptors in the human fetal brain, rats and mice express the glucocorticoid receptor $(r N r 3 c 1)$ in the fetal SCN where it exhibited time of day differences in mRNA expression (69). This contrasts with multiple reports which found no glucocorticoid receptors in the adult $\mathrm{SCN}$, but widespread expression in other tissues $(70,71)$. This may indicate a special role for maternal glucocorticoid control of fetal circadian rhythms during pregnancy.

\section{Evidence Hormone Is Necessary/Sufficient to Entrain Fetus}

Glucocorticoids may act as an entraining agent for the fetus. In vitro work showed that chronic exposure to a glucocorticoid receptor agonist, dexamethasone, lengthened the circadian period, and acute exposure shifted the time of peak PER2 expression depending on the time of day that it was added to fetal mouse SCN explants (69). Unlike dopamine injections during pregnancy, dexamethasone injections cause an acute reduction in $c$-fos expression levels in the fetal SCN (69).

In summary, if, when and how glucocorticoids entrain fetal circadian rhythms remains unknown, but they are wellpositioned to play an important role. Glucocorticoid levels increase in amplitude during the first two-thirds of pregnancy, with no apparent change in the time of their daily peak. They readily cross the placenta to enter the fetal circulation where glucocorticoid receptors are found prior to birth and, when administered to fetal tissue, they can shift circadian rhythms.

\section{OTHER SIGNALS THAT MIGHT INFLUENCE MATERNAL-FETAL CIRCADIAN COMMUNICATION}

To complete this review of potential daily signals from the mother that could impact fetal circadian rhythms and development, we include three additional signals that, while understudied, have shown promise in fulfilling the requirements as circadian coupling factors: progesterone, estrogen, and maternal feeding.

\section{Progesterone and Estrogen \\ Evidence for Rhythmic Expression in Humans and Rodents}

Although serum progesterone and estradiol concentrations have been well characterized across gestation in women and rodents $(36,72,73)$, little is known about the diurnal variation of these hormones before or during pregnancy. In humans, progesterone and estrogen levels progressively increase throughout pregnancy $(74,75)$. One study examined 5 women for diurnal variations in progesterone at 6-10 weeks of gestation and concluded that there was no diurnal variation (25). In a study examining 17 non-pregnant women at different stages of the menstrual cycle, women in the follicular phase displayed diurnal changes in hormone levels with progesterone peaking in the early morning $(\sim$ 10:00 a.m.) and estradiol peaking around 1:00 a.m. Women in the luteal phase did not display diurnal variation in progesterone or estradiol levels (18). However, two other studies of women found diurnal profiles in progesterone levels during the luteal phase with variations in the timing of peak between the women (76) and diurnal profiles of free estradiol throughout their menstrual cycles (77). In pregnant women, serum and urine estradiol concentration in the third trimester exhibited time of day differences, peaking around noon $(24,78)$.

In mice, progesterone levels steadily rise over the course of pregnancy before declining prior to labor (73). Around E18,

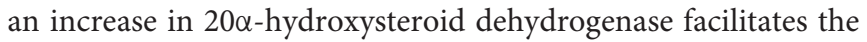
progesterone withdrawal prior to the initiation of parturition (79). One paper that examined serum progesterone levels over two 24-h periods of the rat pregnancy showed that progesterone levels have a peak around ZT9 and a nadir around ZT17 at both E15 and E21 (80). 
To fully explore the potential of maternal and placental hormones in circadian signaling to the fetus, we need more information about their receptor distributions in fetal tissues, their ability to cross the placenta at different times of day, their necessity for circadian gating of birth and fetal circadian rhythms, and their effects on each other. For example, estrogen and progesterone may modulate fetal glucocorticoid levels. In human placental extracts, estrogen, and progesterone reduced $11 \beta$ HSD2 expression which may allow increased transport of glucocorticoids from the mother to the fetus (24).

The placenta has an important role as an endocrine organ, producing hormones that are released into the fetal and maternal circulation (81). The placenta produces progesterone and estrogen and also transports maternally derived hormones into the fetal circulation (81). Some hormones pass through the placenta unchanged, such as melatonin, while others are metabolized into inactive forms, such as glucocorticoids (81). Some placental hormones (e.g., lactogen, growth hormone, and human chorionic gonadotropin) have not been found to exhibit diurnal variations during the latter half of pregnancy (82-84), and thus, would seem less likely to serve as circadian entrainment factors. Because the sources, timing and levels of daily hormone secretion can change throughout pregnancy, we must continue to consider their convergent actions on the proximal factors that entrain fetal circadian rhythms.

\section{Maternal Feeding}

Finally, hormonal rhythms are not the only possible entraining signals. Maternal feeding can act as an entraining signal in certain circumstances $(16,85,86)$. For example, offspring from SCNlesioned dams drank at random times of the day relative to each other, but showed inter- and intra-litter synchronization following 4-h restricted daily feeding during pregnancy (16). The restricted feeding reestablished rhythms in locomotor activity and body temperature in the dam which may have directly, or indirectly, had a role in entraining the pups. In another experiment, when pregnant rats in a light cycle shifted their locomotor activity to anticipate $4 \mathrm{~h}$ of daytime food availability (ZT5-9), the E22 fetal SCN explants showed a similar shift in daily Per1-luc expression (85). Thus, maternal feeding schedules can impact fetal circadian timing, perhaps through humoral or other (e.g., metabolic) pathways. For example, because restricted feeding in non-pregnant SCN lesioned mice can restore daily rhythmicity in corticosterone (87), maternal feeding could act through glucocorticoid signaling to entrain fetal rhythms. How

\section{REFERENCES}

1. Zhang R, Lahens NF, Ballance HI, Hughes ME, Hogenesch JB. A circadian gene expression atlas in mammals: implications for biology and medicine. Proc Natl Acad Sci USA. (2014) 111:16219-24. doi: 10.1073/pnas.1408886111

2. Czeisler CA, Klerman EB. Circadian and sleep-dependent regulation of hormone release in humans. Recent Prog Horm Res. 54, 97-130; discussion 130-132 (1999).

3. Tosini G, Owino S, Guillame J-L, Jockers R. Melatonin receptors: latest insights from mouse models. BioEssays News Rev Mol Cell Dev Biol. (2014) 36:778-87. doi: 10.1002/bies.201400017 and when daily maternal feeding-related signals synchronize fetal circadian rhythms remains to be studied.

\section{CONCLUSION}

Circadian rhythms are important in pregnancy. When development of the fetal circadian system is disturbed, the offspring are at an increased risk for cardiovascular disease, obesity, and other health problems $(88,89)$. Yet, we know little about how the fetus entrains to the mother and how this might impact gestation length. Melatonin, dopamine, and glucocorticoids fulfill many of the criteria for factors that synchronize the offspring. Future studies should elucidate how these hormones change during pregnancy in women. Less invasive methods to measure circadian hormones with high temporal resolution could help us identify pregnancies that are at risk for complications. Additionally, some of these hormones are exogenously administered during pregnancy, but without consideration of their normal diurnal variation. For example, women at risk of preterm birth receive antenatal corticosteroids as part of standard care to improve neonatal outcomes (90). Knowing the appropriate daily profile and roles of glucocorticoids (e.g., in entraining the fetus) could inform the best times of day and doses for steroid treatment to promote fetal development and circadian entrainment. Daily rhythms of maternal and placental signals and their roles in entrainment and birth timing is an area ripe for study and with tremendous potential for translation into clinical care for healthy pregnancies.

\section{AUTHOR CONTRIBUTIONS}

All authors listed have made a substantial, direct and intellectual contribution to the work, and approved it for publication.

\section{FUNDING}

This work was supported by the March of Dimes.

\section{ACKNOWLEDGMENTS}

The authors thank members of the EH and England labs for valuable discussions and the March of Dimes Prematurity Center and Imaging Sciences Training Pathway at Washington University for financial support.

4. Cox KH, Takahashi, J. Circadian clock genes and the transcriptional architecture of the clock mechanism. J Mol Endocrinol. (2019) 64:R93-102. doi: 10.1530/endoabs.59.PL4

5. Takahashi JS. Transcriptional architecture of the mammalian circadian clock. Nat Rev Genet. (2017) 18:164-79. doi: 10.1038/nrg.2016.150

6. Dardente H, Dardente H, Cermakian N. Molecular circadian rhythms in central and peripheral clocks in mammals. Chronobiol Int. (2007) 24:195-213. doi: 10.1080/07420520701283693

7. Arble DM, Ramsey KM, Bass J, Turek FW. Circadian disruption and metabolic disease: Findings from animal models. Best Pract Res Clin Endocrinol Metab. (2010) 24:785-800. doi: 10.1016/j.beem.2010.08.003 
8. Reppert SM, Weaver DR. Coordination of circadian timing in mammals. Nature. (2002) 418:935-941. doi: 10.1038/nature00965

9. Herzog ED. Neurons and networks in daily rhythms. Nat Rev Neurosci. (2007) 8:790-802. doi: 10.1038/nrn2215

10. Swaab DF, Fliers E, Partiman TS. The suprachiasmatic nucleus of the human brain in relation to sex, age and senile dementia. Brain Res. (1985) 342:37-44. doi: 10.1016/0006-8993(85)91350-2

11. Mahoney MM, Ramanathan C, Hagenauer MH, Thompson RC, Smale L, Lee T. Daily rhythms and sex differences in vasoactive intestinal polypeptide, VIPR2 receptor and arginine vasopressin mRNA in the suprachiasmatic nucleus of a diurnal rodent, Arvicanthis niloticus. Eur J Neurosci. (2009) 30:1537-43. doi: 10.1111/j.1460-9568.2009.06936.x

12. Williams WP, Kriegsfeld LJ. Circadian control of neuroendocrine circuits regulating female reproductive function. Front Endocrinol. (2012) 3:60. doi: 10.3389/fendo.2012.00060

13. Le Blond CB, Morris S, Karakiulakis G, Powell R, Thomas PJ. Development of sexual dimorphism in the suprachiasmatic nucleus of the rat. J Endocrinol. (1982) 95:137-45. doi: 10.1677/joe.0.0950137

14. Reppert SM, Schwartz WJ. Maternal coordination of the fetal biological clock in utero. Science. (1983) 220:969-71. doi: 10.1126/science.68 44923

15. Reppert SM, Schwartz WJ. Maternal suprachiasmatic nuclei are necessary for maternal coordination of the developing circadian system. J Neurosci Off J Soc Neurosci. (1986) 6:2724-9. doi: 10.1523/JNEUROSCI.06-09-0272 4.1986

16. Weaver DR, Reppert SM. Periodic feeding of SCN-lesioned pregnant rats entrains the fetal biological clock. Brain Res Dev Brain Res. (1989) 46:291-6. doi: 10.1016/0165-3806(89)90292-7

17. Weaver DR, Keohan JT, Reppert SM. Definition of a prenatal sensitive period for maternal-fetal communication of day length. Am J Physiol. (1987) 253:E701-4. doi: 10.1152/ajpendo.1987.253.6.E701

18. Rahman SA, Grant LK, Gooley JJ, Rajaratnam SMW, Czeisler CA, Lockley SW. Endogenous circadian regulation of female reproductive hormones. $J$ Clin Endocrinol Metab. (2019) 104:6049-59. doi: 10.1210/jc.2019-00803

19. Kivelä A. Serum melatonin during human pregnancy. Acta Endocrinol. (1991) 124:233-7. doi: 10.1530/acta.0.1240233

20. Berga SL, Yen SSC. Circadian pattern of plasma melatonin concentrations during four phases of the human menstrual cycle. Neuroendocrinology. (1990) 51:606-12. doi: 10.1159/000125398

21. Sowers JR, Vlachakis, N. Circadian variation in plasma dopamine levels in man. J Endocrinol Invest. (1984) 7:341-5. doi: 10.1007/BF03351014

22. Van Cauter E, Leproult R, Kupfer DJ. Effects of gender and age on the levels and circadian rhythmicity of plasma cortisol. J Clin Endocrinol Metab. (1996) 81:2468-73. doi: 10.1210/jc.81.7.2468

23. Carr BR, Parker CR, Madden JD, MacDonald PC, Porter JC. Maternal plasma adrenocorticotropin and cortisol relationships throughout human pregnancy. Am J Obstet Gynecol. (1981) 139:416-22. doi: 10.1016/0002-9378(81)9 0318-5

24. Patrick J, Challis J, Campbell K, Carmichael L, Natale R, Richardson $\mathrm{B}$, et al. Circadian rhythms in maternal plasma cortisol and estriol concentrations at 30 to 31,34 to 35 , and 38 to 39 weeks' gestational age. Am J Obstet Gynecol. (1980) 136:325-34. doi: 10.1016/0002-9378(80)9 0857-1

25. Tulchinsky D, Okada DM. Hormones in human pregnancy. IV. Plasma progesterone. Am J Obstet Gynecol. (1975) 121:293-9. doi: 10.1016/0002-9378(75)90001-0

26. Reppert SM, Schwartz WJ. The suprachiasmatic nuclei of the fetal rat: characterization of a functional circadian clock using 14Clabeled deoxyglucose. J Neurosci Off J Soc Neurosci. (1984) 4:1677-82. doi: 10.1523/JNEUROSCI.04-07-01677.1984

27. Jud C, Albrecht U. Circadian rhythms in murine pups develop in absence of a functional maternal circadian clock. J Biol Rhythms. (2006) 21:149-54. doi: $10.1177 / 0748730406286264$

28. Carmona-Alcocer V, Abel JH, Sun TC, Petzold LR, Doyle FJ III, Simms CL' et al. Ontogeny of circadian rhythms and synchrony in the suprachiasmatic nucleus. J Neurosci Off J Soc Neurosci. (2018) 38:1326-34. doi: 10.1523/JNEUROSCI.2006-17.2017
29. Landgraf D, Achten C, Dallmann F, Oster H. Embryonic development and maternal regulation of murine circadian clock function. Chronobiol Int. (2015) 32:416-27. doi: 10.3109/07420528.2014.986576

30. Wreschnig D, Dolatshad H, Davis FC. Embryonic development of circadian oscillations in the mouse hypothalamus. J Biol Rhythms. (2014) 29:299-310. doi: 10.1177/0748730414545086

31. Mark PJ, Crew RC, Wharfe MD, Waddell BJ. Rhythmic three-part harmony: the complex interaction of maternal, placental and fetal circadian systems. $J$ Biol Rhythms. (2017) 32:534-49. doi: 10.1177/0748730417728671

32. Maywood ES, Buttery RC, Vance GH, Herbert J, Hastings MH. Gonadal responses of the male Syrian hamster to programmed infusions of melatonin are sensitive to signal duration and frequency but not to signal phase nor to lesions of the suprachiasmatic nuclei. Biol Reprod. (1990) 43:174-82. doi: 10.1095/biolreprod43.2.174

33. Goldman BD. Mammalian photoperiodic system: formal properties and neuroendocrine mechanisms of photoperiodic time measurement. J Biol Rhythms. (2001) 16:283-301. doi: 10.1177/074873001129001980

34. Tamura H, Takayama H, Nakamura Y, Reiter RJ, Sugino N. Fetal/placental regulation of maternal melatonin in rats. J Pineal Res. (2008) 44:335-40. doi: 10.1111/j.1600-079X.2007.00537.x

35. Montano MM, Wang M-H, Even MD, Vom Saal FS. Serum corticosterone in fetal mice: Sex differences, circadian changes, and effect of maternal stress. Physiol Behav. (1991) 50:323-9. doi: 10.1016/0031-9384(91)90073-W

36. Barkley MS, Geschwind II, Bradford GE. The gestational pattern of estradiol, testosterone and progesterone secretion in selected strains of mice. Biol Reprod. (1979) 20:733-8. doi: 10.1095/biolreprod20.4.733

37. Nakamura Y, Tamura H, Kashida S, Takayama H, Yamagata Y, Karube A, et al. Changes of serum melatonin level and its relationship to feto-placental unit during pregnancy. J Pineal Res. (2001) 30:29-33. doi: 10.1034/j.1600-079X.2001.300104.x

38. Maternal-Fetal Transfer of Melatonin in Pregnant Women Near Term Okatani - 1998. Journal of Pineal Research - Wiley Online Library. Available online at: https://onlinelibrary.wiley.com/doi/abs/10.1111/j.1600-079X.1998. tb00550.x

39. Naitoh N, Watanabe Y, Matsumura K, Murai I, Kobayashi K, Imai-Matsumura $\mathrm{K}$, et al. Alteration by maternal pinealectomy of fetal and neonatal melatonin and dopamine D1 receptor binding in the suprachiasmatic nuclei. Biochem Biophys Res Commun. (1998) 253:850-4. doi: 10.1006/bbrc.1998.9819

40. Lee CK, Moon DH, Shin CS, Kim H, Yoon YD, Kang HS, et al. Circadian expression of Mella and PL-II genes in placenta: effects of melatonin on the PL-II gene expression in the rat placenta. Mol Cell Endocrinol. (2003) 200:57-66. doi: 10.1016/S0303-7207(02)00414-8

41. Davis FC. Melatonin: role in development. J Biol Rhythms. (1997) 12:498-508. doi: 10.1177/074873049701200603

42. Reppert SM, Weaver DR, Rivkees SA, Stopa EG. Putative melatonin receptors in a human biological clock. Science. (1988) 242:78-81. doi: $10.1126 /$ science. 2845576

43. Davis FC, Mannion J. Entrainment of hamster pup circadian rhythms by prenatal melatonin injections to the mother. Am J Physiol. (1988) 255:R43948. doi: 10.1152/ajpregu.1988.255.3.R439

44. Bellavía SL, Carpentieri AR, Vaqué AM, Macchione AF, Vermouth NT. Pup circadian rhythm entrainment-effect of maternal ganglionectomy or pinealectomy. Physiol Behav. (2006) 89:342-9. doi: 10.1016/j.physbeh.2006.06.018

45. Grosse J, Davis FC. Transient entrainment of a circadian pacemaker during development by dopaminergic activation in Syrian hamsters. Brain Res Bull. (1999) 48:185-94. doi: 10.1016/S0361-9230(98)00162-2

46. Viswanathan N, Weaver DR, Reppert SM, Davis FC. Entrainment of the fetal hamster circadian pacemaker by prenatal injections of the dopamine agonist SKF 38393. J Neurosci Off J Soc Neurosci. (1994) 14:5393-8. doi: 10.1523/JNEUROSCI.14-09-05393.1994

47. Reppert SM, Schwartz WJ. Maternal endocrine extirpations do not abolish maternal coordination of the fetal circadian clock. Endocrinology. (1986) 119:1763-7. doi: 10.1210/endo-119-4-1763

48. McNutt CM, Ducsay CA. Catecholamines and uterine activity rhythms in the pregnant rhesus macaque. Biol Reprod. (1991) 45:373-9. doi: 10.1095/biolreprod45.2.373 
49. Hirst JJ, Haluska GJ, Cook MJ, Hess DL, Novy MJ. Comparison of plasma oxytocin and catecholamine concentrations with uterine activity in pregnant rhesus monkeys. J Clin Endocrinol Metab. (1991) 73:804-10. doi: 10.1210/jcem-73-4-804

50. Ben-Jonathan N, Hnasko R. Dopamine as a prolactin (PRL) inhibitor. Endocr Rev. (2001) 22:724-63. doi: 10.1210/edrv.22.6.0451

51. Franchimont $\mathrm{P}$, et al. Prolactin levels during the menstrual cycle*. Clin Endocrinol. (1976) 5:643-50. doi: 10.1111/j.1365-2265.1976.tb03867.x

52. Peleg D, Munsick RA, Diker D, Goldman JA, Ben-Jonathan N. Distribution of catecholamines between fetal and maternal compartments during human pregnancy with emphasis on L-dopa and dopamine. J Clin Endocrinol Metab. (1986) 62:911-4. doi: 10.1210/jcem-62-5-911

53. Ben-Jonathan N, Maxson RE. Elevation of dopamine in fetal plasma and the amniotic fluid during gestation. Endocrinology. (1978) 102:649-52. doi: 10.1210/endo-102-2-649

54. Ben-Jonathan N. Dopamine: a prolactin-inhibiting hormone. Endocr Rev. (1985) 6:564-89. doi: 10.1210/edrv-6-4-564

55. Inoue $\mathrm{K}$, Kudo $\mathrm{T}$, Kishimoto $\mathrm{Y}$. The production mechanism of amniotic fluid dopamine in rats. Asia-Oceania J Obstet Gynaecol. (1991) 17:349-55. doi: 10.1111/j.1447-0756.1991.tb00285.x

56. Watanabe T, Matsuhashi K, Takayama S. Placental and blood-brain barrier transfer following prenatal and postnatal exposures to neuroactive drugs: relationship with partition coefficient and behavioral teratogenesis. Toxicol Appl Pharmacol. (1990) 105:66-77. doi: 10.1016/0041-008X(90)90359-3

57. Shearman LP, Zeitzer J, Weaver DR. Widespread expression of functional D1-dopamine receptors in fetal rat brain. Brain Res Dev Brain Res. (1997) 102:105-15. doi: 10.1016/S0165-3806(97)00091-6

58. Weaver DR, Rivkees SA, Reppert SM. D1-dopamine receptors activate c-fos expression in the fetal suprachiasmatic nuclei. Proc Natl Acad Sci USA. (1992) 89:9201-4. doi: 10.1073/pnas.89.19.9201

59. Rivkees SA, Lachowicz JE. Functional D1 and D5 dopamine receptors are expressed in the suprachiasmatic, supraoptic, and paraventricular nuclei of primates. Synap NYN. (1997) 26:1-10. doi: 10.1002/(SICI)10982396(199705)26:1<1::AID-SYN1>3.0.CO;2-D

60. Viswanathan N, Davis FC. Single prenatal injections of melatonin or the D1-dopamine receptor agonist SKF 38393 to pregnant hamsters sets the offsprings' circadian rhythms to phases 180 degrees apart. J Comp Physiol. (1997) 180:339-46. doi: 10.1007/s003590050053

61. Iuvone PM, Gan J. Functional interaction of melatonin receptors and D1 dopamine receptors in cultured chick retinal neurons. J Neurosci Off J Soc Neurosci. (1995) 15:2179-85. doi: 10.1523/JNEUROSCI.15-03-02179.1995

62. Engeland WC, Arnhold MM. Neural circuitry in the regulation of adrenal corticosterone rhythmicity. Endocrine. (2005) 28:325-32. doi: 10.1385/ENDO:28:3:325

63. Moore RY, Eichler VB. Loss of a circadian adrenal corticosterone rhythm following suprachiasmatic lesions in the rat. Brain Res. (1972) 42:201-6. doi: 10.1016/0006-8993(72)90054-6

64. Ballard PL. Hormonal control of lung maturation. Baillieres Clin Endocrinol Metab. (1989) 3:723-53. doi: 10.1016/S0950-351X(89) 80051-5

65. Majumdar AP, Nielsen H. Influence of glucocorticoids on prenatal development of the gut and pancreas in rats. Scand J Gastroenterol. (1985) 20:65-71. doi: 10.3109/00365528509089634

66. Venihaki M, Carrigan A, Dikkes P, Majzoub JA. Circadian rise in maternal glucocorticoid prevents pulmonary dysplasia in fetal mice with adrenal insufficiency. Proc Natl Acad Sci USA. (2000) 97:7336-41. doi: $10.1073 /$ pnas.97.13.7336

67. Muglia L, Jacobson L, Dikkes P, Majzoub JA. Corticotropin-releasing hormone deficiency reveals major fetal but not adult glucocorticoid need. Nature. (1995) 373:427-32. doi: 10.1038/373427a0

68. Edwards CR, Benediktsson R, Lindsay RS, Seckl JR. 11 beta-Hydroxysteroid dehydrogenases: key enzymes in determining tissue-specific glucocorticoid effects. Steroids. (1996) 61:263-9. doi: 10.1016/0039-128X(96)00033-5

69. Cečmanová V, Houdek P, Šuchmanová K, Sládek M, Sumová A. Development and entrainment of the fetal clock in the suprachiasmatic nuclei: the role of glucocorticoids. J Biol Rhythms. (2019) 34:307-22. doi: $10.1177 / 0748730419835360$
70. Rosenfeld P, Van Eekelen JAM, Levine S, De Kloet ER. Ontogeny of the type 2 glucocorticoid receptor in discrete rat brain regions: an immunocytochemical study. Dev Brain Res. (1988) 42:119-27. doi: 10.1016/0165-3806(88)9 0207-6

71. Balsalobre A, Brown SA, Marcacci L, Tronche F, Kellendonk C, Reichardt $\mathrm{HM}$, et al. Resetting of circadian time in peripheral tissues by glucocorticoid signaling. Science. (2000) 289:2344-7. doi: 10.1126/science.289.548 8.2344

72. Michael SD, Geschwind II, Bradford GE, Stabenfeldt GH. Pregnancy in mice selected for small litter size: reproductive hormone levels and effect of exogenous hormones. Biol Reprod. (1975) 12:400-7. doi: 10.1095/biolreprod12.3.400

73. Murr SM, Stabenfeldt GH, Bradford GE, Geschwind II. Plasma progesterone during pregnancy in the mouse. Endocrinology. (1974) 94:1209-11. doi: 10.1210/endo-944-1209

74. Tulchinsky D, Hobel CJ, Yeager E, Marshall JR. Plasma estrone, estradiol, estriol, progesterone, and 17-hydroxyprogesterone in human pregnancy. I. Normal pregnancy. Am J Obstet Gynecol. (1972) 112:1095-100. doi: 10.1016/0002-9378(72)90185-8

75. Johansson ED. Plasma levels of progesterone in pregnancy measured by a rapid competitive protein binding technique. Acta Endocrinol. (1969) 61:60717. doi: $10.1530 /$ acta. 0.0610607

76. Veldhuis JD, Christiansen E, Evans WS, Kolp LA, Rogol AD, Johnson ML. Physiological profiles of episodic progesterone release during the midluteal phase of the human menstrual cycle: analysis of circadian and ultradian rhythms, discrete pulse properties, and correlations with simultaneous luteinizing hormone release. J Clin Endocrinol Metab. (1988) 66:414-21. doi: 10.1210/jcem-66-2-414

77. Bao A-M, Liu RY, van Someren EJ, Hofman MA, Cao YX, Zhou JN. Diurnal rhythm of free estradiol during the menstrual cycle. Eur J Endocrinol. (2003) 148:227-32. doi: 10.1530/eje.0.1480227

78. Townsley JD, Dubin NH, Grannis GF, Gartman LJ, Crystle CD. Circadian rhythms of serum and urinary estrogens in pregnancy. J Clin Endocrinol Metab. (1973) 36:289-95. doi: 10.1210/jcem-36-2-289

79. Telleria CM, Parmer TG, Zhong L, Clarke DL, Albarracin CT, Duan WR, et al. The different forms of the prolactin receptor in the rat corpus luteum: developmental expression and hormonal regulation in pregnancy. Endocrinology. (1997) 138:4812-20. doi: 10.1210/endo.138.1 1.5479

80. Crew RC, Mark PJ, Clarke MW, Waddell BJ. Obesity disrupts the rhythmic profiles of maternal and fetal progesterone in rat pregnancy. Biol Reprod. (2016) 95:55. doi: 10.1095/biolreprod.116.139451

81. Fowden AL, Forhead AJ. Endocrine mechanisms of intrauterine programming. Reproduction. (2004) 127:515-26. doi: 10.1530/rep.1.00033

82. Pekonen F, Alfthan H, Stenman UH, Ylikorkala O. Human chorionic gonadotropin (hCG) and thyroid function in early human pregnancy: circadian variation and evidence for intrinsic thyrotropic activity of hCG. $J$ Clin Endocrinol Metab. (1988) 66:853-6. doi: 10.1210/jcem-66-4-853

83. Eriksson L, Frankenne F, Edèn S, Hennen G, Von Schoultz B. Growth hormone 24-h serum profiles during pregnancy-lack of pulsatility for the secretion of the placental variant. $\mathrm{Br} J$ Obstet Gynaecol. (1989) 96:949-53. doi: 10.1111/j.1471-0528.1989.tb 03352.x

84. Houghton DJ, Newnham JP, Lo K, Rice A, Chard T. Circadian variation of circulating levels of four placental proteins. BJOG Int J Obstet Gynaecol. (1982) 89:831-5. doi: 10.1111/j.1471-0528.1982.tb05035.x

85. Ohta $\mathrm{H}, \mathrm{Xu} \mathrm{S}$, Moriya T, Iigo M, Watanabe T, Nakahata N, Chisaka H, et al. Maternal feeding controls fetal biological clock. PLOS ONE. (2008) 3:e2601. doi: 10.1371/journal.pone.0002601

86. Canaple L, Gréchez-Cassiau A, Delaunay F, Dkhissi-Benyahya O, Samarut J. Maternal eating behavior is a major synchronizer of fetal and postnatal peripheral clocks in mice. Cell Mol Life Sci CMLS. (2018) 75:3991-4005. doi: 10.1007/s00018-018-2845-5

87. Krieger DT, Hauser H, Krey LC. Suprachiasmatic nuclear lesions do not abolish food-shifted circadian adrenal and temperature rhythmicity. Science. (1977) 197:398-9. doi: 10.1126/science.877566 
88. Serón-Ferré M, Mendez N, Abarzua-Catalan L, Vilches N, Valenzuela FJ, Reynolds HE, et al. Circadian rhythms in the fetus. Mol Cell Endocrinol. (2012) 349:68-75. doi: 10.1016/j.mce.2011.07.039

89. Varcoe TJ, Gatford KL, Kennaway DJ. Maternal circadian rhythms and the programming of adult health and disease. Am J Physiol Regul Integr Comp Physiol. (2018) 314:R231-41. doi: 10.1152/ajpregu.0024 8.2017

90. Hrabalkova L, Takahashi T, Kemp MW, Stock SJ. Antenatal corticosteroids for fetal lung maturity - too much of a good thing? Curr Pharm Des. (2019) 25:593-600. doi: 10.2174/1381612825666190326143814
Conflict of Interest: The authors declare that the research was conducted in the absence of any commercial or financial relationships that could be construed as a potential conflict of interest.

Copyright (c) 2020 Bates and Herzog. This is an open-access article distributed under the terms of the Creative Commons Attribution License (CC BY). The use, distribution or reproduction in other forums is permitted, provided the original author(s) and the copyright owner(s) are credited and that the original publication in this journal is cited, in accordance with accepted academic practice. No use, distribution or reproduction is permitted which does not comply with these terms. 